\section{Commentary: The Holy Grail quest for the perfect aortic valve prosthesis}

\author{
Edgar Aranda-Michel, BS, ${ }^{\mathrm{a}}$ and \\ Ibrahim Sultan, MD ${ }^{\mathrm{a}, \mathrm{b}}$
}

The choice of prosthetic valve type for a surgical aortic valve replacement is a nuanced decision-no perfect valve currently exists. The Holy Grail in this setting is a prosthesis with the durability of a mechanical valve coupled with the thrombotic burden of a bioprosthetic valve. In this edition of the Journal, Schaller and colleagues ${ }^{1}$ have set out on this quest by presenting a novel trileaflet hinged mechanical valve constructed from polyether-ether-ketone (PEEK). Their design combines the hinged joint of mechanical valves with the topography of bioprosthetic valves with one critical difference, the location of this joint. The pivot point of these joints has been moved from the periphery-current mechanical valve placement-to the central outflow tract region. This exposes the joint to greater systolic flows, conceptually aiding in washing them out and reducing thrombus risk. The authors present up to 1-year sheep studies and show favorable hemodynamics $(<6 \mathrm{~mm}$ $\mathrm{Hg}$ mean transvalvular gradients) with low thrombotic events. Just as there was substantial evolution from the caged ball valves to the current bileaflet mechanical valves, major iteration changes for mechanical valves like this have not happened since.

The thromboembolic and bleeding risk of surgically implanted aortic valves is one of the main considerations in selecting either a mechanical or bioprosthetic valve-the

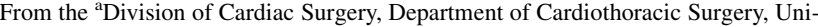
versity of Pittsburgh; and ${ }^{\mathrm{b}}$ Heart and Vascular Institute, University of Pittsburgh Medical Center, Pittsburgh, Pa.

Disclosures: The authors reported no conflicts of interest.

The Journal policy requires editors and reviewers to disclose conflicts of interest and to decline handling or reviewing manuscripts for which they may have a conflict of interest. The editors and reviewers of this article have no conflicts of interest.

Received for publication May 31, 2021; revisions received May 31, 2021; accepted for publication June 1, 2021; available ahead of print June 16, 2021.

Address for reprints: Ibrahim Sultan, MD, Division of Cardiac Surgery, Department of Cardiothoracic Surgery, University of Pittsburgh, Center for Thoracic Aortic Disease, Heart and Vascular Institute, University of Pittsburgh Medical Center, 5200 Centre Ave, Suite 715, Pittsburgh, PA 15232 (E-mail: sultani@upmc.edu). JTCVS Open 2021;7:89-90

2666-2736

Copyright (c) 2021 The Author(s). Published by Elsevier Inc. on behalf of The American Association for Thoracic Surgery. This is an open access article under the CC BY-NC-ND license (http://creativecommons.org/licenses/by-nc-nd/4.0/).

https://doi.org/10.1016/j.xjon.2021.06.002
}

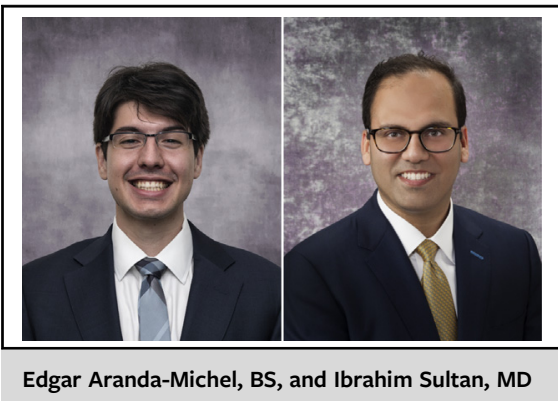

\section{CENTRAL MESSAGE \\ A mechanical heart valve in the aortic position with central hinges may reduce thromboem- bolic burden associated with mechanical prostheses.}

other is structural valve degeneration. ${ }^{2}$ Current guidelines recommend a mechanical valve in patients younger than 50 years of age based on a lower bleeding risk compared with structural valve deterioration necessitating reintervention. $^{3-5}$ The material choices of both categories of devices drive their different longevity and thrombogenicity. Bioprosthetic valves are typically constructed from bovine or porcine tissue. As such, they are more resilient to thrombus formation due to endothelization, but due to not being natively subjected to the same biomechanical forces as the human aortic valve, they have a greater propensity for degradation. Contrasting this, mechanical valves are often made with titanium or carbonconsiderably strong materials. As this material is not biologic, thrombus can easily form via thermodynamically favorable platelet adhesion. PEEK is an attractive material to use to make valves, and it has been gaining increased use in the medical device space. Particularly, due to its favorable mechanical properties, PEEK has been gaining use in orthopedics for spine implants and total knee replacements. ${ }^{6}$ Given the general inert characteristics of PEEK to blood and biological tissues, ${ }^{6,7}$ it is evident why PEEK would represent a good evolution in mechanical valve materials.

One critical finding of the study, as mentioned by the authors, is the presence of fibrin deposits on the surfaces of the valves in the setting of no anticoagulation or antiplatelet therapy. This thrombogenic burden, along with other trileaflet mechanical valve studies, suggests that at a minimum, antiplatelet therapy is necessary for long-term use of these novel valves. ${ }^{8}$ However, this is not necessarily a detriment 
to this technology, as it would ameliorate the oftenburdensome need of vitamin $\mathrm{K}$ antagonist therapy with typical mechanical aortic valves. Moreover, antiplatelet therapy is already indicated in patients with a bioprosthetic device. Thus, this novel device has the potential of maintaining the antiplatelet burden of current bioprosthetic valves, increasing the valve integrity to that of current mechanical valves, all while negating the need of anticoagulation.

While promising, these results need to be met with hesitation. The presented studies in animals are in a limited number of sheep models such that no statistical analysis could be conducted. More robust animal experiments with appropriate control groups are warranted to assess the true thrombotic burden of this new valve, both from a material and leaflet design standpoint. Nevertheless, the authors should be congratulated on a tireless pursuit of this technology in hopes of changing the landscape for surgical aortic valves.

\section{References}

1. Schaller T, Scharfschwerdt M, Schubert K, Prinz C, Lembke U, Sievers H-H. Aortic valve replacement in sheep with a novel trileaflet mechanical heart valve prosthesis without anticoagulation. J Thorac Cardiovasc Surg Open. 2021;7: 76-88.

2. Head SJ, Çelik M, Kappetein AP. Mechanical versus bioprosthetic aortic valve replacement. Eur Heart J. 2017;38:2183-91.

3. Otto CM, Nishimura RA, Bonow RO, Carabello BA, Erwin JP, Gentile F, et al. 2020 ACC/AHA guideline for the management of patients with valvular heart disease: a report of the American College of Cardiology/American Heart Association joint committee on clinical practice guidelines. Circulation. 2021;143:e72-227.

4. Kilic A, Sultan I, Navid F, Aranda-Michel E, Chu D, Thoma F, et al. Trifecta aortic bioprosthesis: midterm results in 1,953 patients from a single center. Ann Thorac Surg. 2019;107:1356-62.

5. Huckaby LV, Sultan I, Gleason TG, Chen S, Thoma F, Navid F, et al. Outcomes of tissue versus mechanical aortic valve replacement in patients 50 to 70 years of age. J Card Surg. 2020;35:2589-97.

6. Kurtz SM, Devine JN. PEEK biomaterials in trauma, orthopedic, and spinal implants. Biomaterials. 2007;28:4845-69.

7. Song J, Liao Z, Shi H, Xiang D, Xu L, Liu Y, et al. Blood compatibility of ZrO2 particle reinforced PEEK coatings on Ti6Al4V substrates. Polymers. 2017;9:589.

8. Gallegos RP, Rivard AL, Suwan PT, Black S, Bertog S, Steinseifer U, et al. In-vivo experience with the Triflo trileaflet mechanical heart valve. J Heart Valve Dis. 2006;15:791-9. 